\begin{tabular}{c} 
Volume and Issues Obtainable at Center for Sustainability Research and Consultancy \\
Journal of Business and Social Review in Emerging Economies \\
ISSN: 2519-089X \& ISSN (E): 2519-0326 \\
Volume 7: Issue 4 December 2021 \\
CSRட \\
Journal homepage: www.publishing.globalcsrc.org/jbsee \\
\hline
\end{tabular}

\title{
Does Social Media Provoked to Cyber Deception? An Illustrative Based Study of Youth
}

Nasar Shah, MPhil Scholar, Department of Rural Sociology, The University of Agriculture Peshawar Pakistan

Muhammad Jawad, Department of Rural Sociology, University of Agriculture Peshawar Pakistan

Younas Khan, Lecturer, Department of Sociology and Political Science, Bacha Khan University Charsadda, Pakistan

Syed Zuhaib Aziz, Department of Sociology, University of Peshawar, Pakistan

*Corresponding author's email: khansoc5@gmail.com

\begin{tabular}{l}
\hline ARTICLE DETAILS \\
\hline History \\
Revised format: Nov 2021 \\
Available Online: Dec 2021 \\
\hline Keywords \\
Cyber Deception, \\
Social Media, \\
Deviance, Youth \\
\hline JEL Classification \\
Z13, A14
\end{tabular}

\section{ABSTRACT}

Purpose: The present study was conducted with the sole aim to explore the role of social media in promotion of cyber deception among youth which further lead to deviance among the existing societal order.

Methodology: sample size of 354 respondents (youth) were randomly selected for taking primary data through structured questionnaire technique. Further, the primary data was coded into SPSS for further analysis in terms of descriptive and inferential statistics

Findings: Based on the study results, the study explored that cyber deception caused by the excessive usage of social media which further lead to psychological and physical problems among youth. Moreover, virtual social world and social games are the stakeholders of cyber deception; online shopping of various companies intentionally did cyber deception; content communities and social networking users are the major deception; youth are sharing fake picture from their profile for deception. Likewise, the study also explored that manipulation of sender identity information. Female are more indulged in deceptive behavior than male, usually girl's misuse of social media sites to influence and cash wealthy and loved ones and kidnaping is done through cyber deception

Implications: Thus keeping in view the above results, the government should make such polices to overcome on the premises of the study in an urgent basis with corroboration to busy the future generation in more positive ground on sustainable development projects were the order of the day, along with parents must focus on their youth in terms of proper check and balance on weekly basis with corroboration of proper socialization will subjugate the tumbling factor in today world i.e., cyber deception

\section{OPEN ACCESS}

(C) 2021 The authors, under a Creative Commons Attribution-

NonCommercial 4.0

Recommended citation: Shah, N., Jawad, M., Khan, Y. and Aziz, S. Z. (2021). Does Social Media Provoked to Cyber Deception? An Illustrative Based Study of Youth. Journal of Business and Social Review in Emerging Economies, 7 (4), 977-983. 


\section{Introduction}

\section{Cyber Deception}

Deception is defined as the ability to detect deception through certain means. Fraudulent detection ideas are classified as reward indicators and strategic decisions. Symptoms of leaks show sincere intention of someone, that attempts to clarify the another person's speech, for instance small expressions. Besides, strategic verdicts are intended to be transmitted by the swindler in order to succeed in their deception (Humpherys et al., 2011). In order to detect fraud, user behavior is used. The use of hand and facial expression by the user is one of the method adopted by Blob for recognizing the fraud ( $\mathrm{Lu}$ et al., 2005). In addition, the following ideas are also used to perceive fraud. They are "Interpersonal Deception Theory (IDT), Leakage Theory (LT), and Expectancy Violations Theory (EVT)" (Burgoon et al., 2005). Two researchers conducted a study on IDT and found that the method is driven by policy. IDT makes it seem that deception is a strategic activity under various detection systems. Leaked theory is also used to detect fraudulent indicators but these are automatically introduced by the fraudster due to the inability to reconstruct the equivalent of true behavior (Tsikerdekis and Zeadally, 2014).

Sock puppet cases include text from real users who deliberately create multiple identities and deliberately try to hide their relationship with the sock pup master. Thus through this chorus researchers can easily explore the writing style of each user and acquire multiple identities (Solorio et al., 2013). Stylometry is a method of forensics that helps security researchers finds ownership of anonymous documents. It answers questions such as, "Who is the author of the document?" (Afroz et al., 2012). Now a day, the association protection media are exceptionally worried about individuals being acquainted with a wide extent of maltreatment through Online Media Stages. The unsafe target of people beguiling different people develops a modernized risk that is perhaps the most hard to battle. Significantly more by and large, these high level dangers are annoyed with the sheer number of inadequacies present in social media (SM), the measure of accessible and various types of SM, the vulnerable game plan and improvement of SM, the giant volumes of unstructured substance, and the chances that SM accommodate people acting noxiously (Assunção et al., 2015; Haimson and Hoffmann, 2016; Chaffey, 2016). These sections all add to SM being unimaginably vulnerable against modernized hazards accomplished by noxious clients. Likewise, because of these high level dangers and SM deficiencies we witness a disturbing improvement in the greatness of mechanized tormenting, data blackmail, character copy, dispersal of sexual redirection, trickiness (Galán-García et al., 2015; Smit, 2015; Gurajala et al., 2015; Kabay et al., 2014).

Electronic dating deception has been the place of intermingling of considered different scientists. For instance, people introduce themselves truly in their electronic dating profiles. They found that individuals purposefully deceive and accepted that trickery on certain person ascribes like picture, locale, age and sexual bearing, are more ordinary (Toma et al., 2008). Equivalent appraisal on web based dating extortion in any case rotated around the photographs introduced on these electronic dating profiles alone (Hancock and Toma, 2009). During another agent screening could effectively see people admitting all from individuals (Nahari et al., 2016). Past criminal records and contemplated the information equipped by the culprits with the authentic information. The information they got familiar a development with show the person credits about which these criminals were all around made a beeline for lie. It was discovered that criminals most reliably lied about their name (Wang et al., 2006). Keeping in view the above stock of literature, the present study was designed to explore the role of social media in the view of cyber deception through sociological and criminological lens. Moreover, this article tries to explore the aforementioned problem through associational and perceptional research methods i.e. chi-square test statistics, repressively. 


\section{Material and Methods}

A cross sectional based study was conducted in district Dir lower Khyber PukhtunKhwa (KPK) Pakistan. A sample size of 354 respondent (youth) out of total 4468 population was selected randomly as per Sekaran (2003) criteria. The primary data was collected through structured questionnaire from two government collages i.e., Government Post Graduate College Timergara (GPGCT) and Government Girls Degree College Timergara (GGDCT) respectively. After data collection, the data was coded into Statistical Packages for Social Sciences (SPSS) to determine the results in terms of descriptive and inferential statistics. The results of univariate were obtained in the form of frequency and percentages while the result of bivariate analysis, chi-square test statistics was used to measure the association between dependent (deviance) and independent variable (cyber deception).

\section{Result and Discussion \\ Descriptive Statistics Explanation}

Table 1 depicted that majority of the sampled respondents 88.7 percent were using social media sites, 70.1 percent were agreed that excessive usage of social media provoked to deviant behavior at macro and micro level, and 68.6 percent were agreed that deviant behavior on social media create a psychological and social disorder at societal and individual level. Likewise in the next statement that media addiction due to excessive usage of social media drastically affects academic performance, as witnessed by Nain, (2014) that, excessive use of social media is a waste of time and has a detrimental effect on health student's academic performance as well. 68.6 percent of the respondents were agreed with the statement, 74.3 percent were agreed that academic performance is weak due to excessive usage of social media sites at formal and informal learning setup and 75.4 percent of the respondents were agreed, social media usage had negative effects on student's social behavior in daily life. These results were also in line with Nain (2014) who disclosed that the excessive usage of social media wasting the time and worsen youth social behavior and student's academic performance at school which lead to deviance among them in present and future scenario. Moreover, majority of the sampled respondents 52.5 percent were disagree that victimization through online harassment leads to socio-psychological dysfunctional. It could be deduced from these findings that online victimization were not perpetuated in the study area. However, the current results were not similar outlook with Keijsers et al., (2012) and Ybarra et al., (2007) who disclosed that social media usage harassment like in the shape of face to face victimization the negative consequences associated with it. Likewise majority of the respondents 58.5 percent were agreed that excessive social media often lead toward inclination of drugs and others substance abuse in your area and 66.4 percent of the respondents disclosed that juvenile delinquency caused due to the excessive usage of social media by both parents and teachers. It could be inferred from these results that, parents and teachers excessive usage of social media instead of their concerned duty i.e., socialization of younger generation in day to day life further worsen the career of the youth (Hirschi, 2001).

Table 1: Perception of the Respondents Regarding Dependent Variable (Deviance among Youth)

\begin{tabular}{|l|l|l|l|}
\hline Statement & Agree (\%) & Disagree (\%) & Total (\%) \\
\hline Are you using any social media sites? & $314(88.7)$ & $40(11.3)$ & $354(100)$ \\
\hline $\begin{array}{l}\text { Excessive usage of social media provoked to deviant } \\
\text { behavior at macro and micro level. }\end{array}$ & $248(70.1)$ & $106(29.9)$ & $354(100)$ \\
\hline $\begin{array}{l}\text { Deviant behavior on social media creates a psychological and } \\
\text { social disorder? }\end{array}$ & $225(63.6)$ & $129(36.4)$ & $354(100)$ \\
\hline $\begin{array}{l}\text { Media addiction due to excessive usage of social media } \\
\text { drastically affects academic performance. }\end{array}$ & $243(68.6)$ & $111(31.4)$ & $354(100)$ \\
\hline $\begin{array}{l}\text { Academic performance is weak due to excessive usage of } \\
\text { social media sites at formal and informal learning setup. }\end{array}$ & $263(74.3)$ & $91(25.7)$ & $354(100)$ \\
\hline Do you agree that social media usage had negative effects on & $267(75.4)$ & $87(24.6)$ & $354(100)$ \\
\hline
\end{tabular}




\begin{tabular}{|l|l|l|l|}
\hline student's social behavior in daily life? & & & \\
\hline $\begin{array}{l}\text { Are you become a victim of any online harassment, which led } \\
\text { to socio-psychological dys-functionalism? }\end{array}$ & $168(47.5)$ & $186(52.5)$ & $354(100)$ \\
\hline $\begin{array}{l}\text { Do you agree that excessive social media often lead toward } \\
\text { inclination of drugs and others substance abuse in your area? }\end{array}$ & $207(58.5)$ & $147(41.5)$ & $354(100)$ \\
\hline $\begin{array}{l}\text { Juvenile delinquency is caused due to excessive usage of } \\
\text { social media by parents \& teachers. }\end{array}$ & $235(66.4)$ & $119(33.6)$ & $354(100)$ \\
\hline
\end{tabular}

\section{Association between CD and Deviant Behavior (DB)}

Table 2 explored the association between dependent variable (deviant behavior) and independent variable (Cyber Deception) through associational test i.e., chi-square test statistics. A highly significant association $(\mathrm{P}=0.000)$ was found between $\mathrm{DB}$ that $\mathrm{CD}$ is caused through the excessive usage of social media it could be deduced from these findings that $\mathrm{CD}$ at social media sites contributed to negative reper causation at societal and individual level. As these results were also similar with Ma and Lei (2010) \& Jin et al. (2021) who disclosed that in China, there are three types of CDB (cyber deviant behavior) are found among youth, $\mathrm{CF}$ (cyber flaming) and $\mathrm{CP}$ (cyber pornography) and $\mathrm{CD}$ (cyber deception) due to the excessive usage of social media. Moreover a highly significant association $(\mathrm{P}=0.000)$ was found between $\mathrm{DB}$ and Cyber deception leads to psychological and physical problem. It could be inferred from these findings that mental and physical health worsens day by day due to CD in the existing society. This statement was also supported by Roberts and Dunbar (2010) disclosed that, social media sites affect our youngers socially, emotionally, physically and the huge time of their life in cognitive development deteriorate due to CD. Similarly in the next statement that virtual social world and social games are the stakeholders of cyber deception and DB was found a non-significant association $(\mathrm{P}=0.386)$ it could be deduced from the above inferences that excessive usage of social media effects younger generations in term of all institutional structure in the current scenario. Furthermore, a highly significant association $(\mathrm{P}=0.000)$ was found between $\mathrm{DB}$ and online shopping of various companies intentionally did CD. This statement is not in line with Kaplan et al., (2010) and Lenhart \& Madden, (2007), who dismantled that online business is done through SM sites by the youth, which have access to different technologies for keeping them connected through these sites with each other, so the usage of SM sites is rapidly grown in children, elders and especially in youth worldwide, empowering new chances for self-promoting learning and making a wide level relation and interaction and the controlling of discretion and closeness. Moreover a non-significant association $(\mathrm{P}=0.908)$ was found between $\mathrm{DB}$ and content communities and social networking users are the major deception. This statement was line with Wang et al., (2006) who explored that content communities and social networking users are the major deception in today era. Likewise highly significant association $(\mathrm{P}=0.000)$ was found between DB and youth are sharing fake picture from their profile for deception. It could be inferred from such findings that due to the excessive usage of SM sites new deceptions activities were awakened which further lead to dysfunctionalism at community and individual level, as Kapidzic and Herring (2014) dismantled that young people pick their profile pictures as solicitations to interface with others, and their decisions address socially predominant belief systems of sexual orientation and race as built up by broad communications pictures. Moreover a highly significant association $(\mathrm{P}=0.000)$ was found between $\mathrm{DB}$, manipulation of sender identity information, content, and communication channel with low difficulty lead to high deception on social media and DB. These results were also in line with Brickman-Bhutta, (2009) and Fox et al., (2007) who disclosed that, online chatting, calling and sharing of media and leaking of personal information and communication to the unknown people will need further research in the same field. Notwithstanding, non-significant association $(\mathrm{P}=0.634)$ was found between $\mathrm{DB}$ and female are more indulged in deceptive behavior than male. These findings are supported by Mitchell et al., (2014) who disclosed that young girls are get more inappropriate behavior in examination with young men. Similarly, a highly significant association $(\mathrm{P}=0.000)$ was found between DB and usually girl's misuse of social media sites to influence and cash wealthy and 
loved ones, These results was supported by Kim (2004) stated that ladies may post hot pictures of themselves online in light of the fact that it causes them to feel engaged. For instance, young ladies who much of the time read cosmopolitan or excitement are bound to see sex as a fun, easygoing action and were stronger of ladies assuming responsibility in sexual connections. Lastly a highly significant association $(\mathrm{P}=0.000)$ was found between $\mathrm{DB}$ and Kidnaping is done through $\mathrm{CD}$, which is sub type of social media.

Table 2: Association between independent variable (cyber deception) with dependent variable deviant behavior

\begin{tabular}{|c|c|c|}
\hline Statement & Dependent variable & Chi-square \& P value \\
\hline $\begin{array}{l}\text { Cyber deception is caused through the excessive usage of } \\
\text { social media. }\end{array}$ & \multirow{10}{*}{$\begin{array}{l}\text { Deviant Behavior } \\
\text { among youth }\end{array}$} & $x^{2}=88.031 ; \mathrm{P}=0.000$ \\
\hline Cyber deception leads to psychological and physical problem. & & $x^{2}=98.483 ; \mathrm{P}=0.000$ \\
\hline $\begin{array}{l}\text { Virtual social world and social games are the stakeholders of } \\
\text { cyber deception. }\end{array}$ & & $x^{2}=.786 ; \mathrm{P}=0.386$ \\
\hline $\begin{array}{l}\text { Online shopping of various companies intentionally did cyber } \\
\text { deception. }\end{array}$ & & $x^{2}=76.599 ; \mathrm{P}=0.000$ \\
\hline $\begin{array}{l}\text { Content communities and social networking users are the major } \\
\text { deception. }\end{array}$ & & $x^{2}=.028 ; \mathrm{P}=0.908$ \\
\hline Youth are sharing fake picture from their profile for deception. & & $\left.x^{2}=51.400 ; \mathrm{P}=0.000\right)$ \\
\hline $\begin{array}{l}\text { Manipulation of sender identity information, content, and } \\
\text { communication channel with low difficulty lead to high } \\
\text { deception on social media. }\end{array}$ & & $x^{2}=1.669 ; \mathrm{P}=0.210$ \\
\hline Female are more indulged in deceptive behavior than male. & & $x^{2}=.314 ; \mathrm{P}=0.634$ \\
\hline $\begin{array}{l}\text { Usually girl's misuse of social media sites to influence and } \\
\text { cash wealthy and loved ones. }\end{array}$ & & $x^{2}=45.461 ; \mathrm{P}=0.000$ \\
\hline $\begin{array}{l}\text { Kidnaping is done through cyber deception, which is sub type } \\
\text { of social media. }\end{array}$ & & $x^{2}=53.264 ; \mathrm{P}=0.000$ \\
\hline
\end{tabular}

\section{Conclusion}

A cross sectional based study was conducted to explore the CD through perceptional based study in district Dir lower Pakistan. Based on the study dynamics the study found that CD is caused through the excessive usage of SM which further worsen the socio-psychological wellbeing of the societal members at macro and micro level. Moreover, virtual and social world, social games, online shopping companies, content communities and social networking uses are the major symbolize through cyber deception scenario. Moreover, the study also explored, that manipulation of sender identity information, content and communication channel disrupted the societal equilibrium i.e., female are more indulged in deceptive behavior than male, as usually girls misuse the social media sites to influence and cash wealthy and loved one and lastly kidnaping in also done through CD in the study area. Thus, parents should motivate their youth to use internet and other media sources only for the purpose of education, while in educational institution teachers to encourage students to improve their knowledge through internet irrespective of involvement in those sites which cradle into CD which is cry of the day of every society around the globe. A proper check and balance by the parents in familial life and teachers at schooling life will positively contributed to overcome on the surging issue of CD is the order of the day. Lastly, the government should also make policies pertaining to CD cases more severe, along with ban on such websites which further lightened the CD endeavor.

\section{References}

Afroz, S., Brennan, M., \& Greenstadt, R. (2012, May). Detecting hoaxes, frauds, and deception in writing style online. In 2012 IEEE Symposium on Security and Privacy (pp. 461-475). IEEE.

Assunção, M. D., Calheiros, R. N., Bianchi, S., Netto, M. A., \& Buyya, R. (2015). Big Data 
computing and clouds: Trends and future directions. Journal of Parallel and Distributed Computing, 79, 3-15.

Banyard, V. L., Moynihan, M. M., \& Plante, E. G. (2007). Sexual violence prevention through bystander education: An experimental evaluation. Journal of community psychology, 35(4), 463-481.

Brickman-Bhutta, C. (2009). Not by the book: Facebook as sampling frame. Disponible online en: www. thearda. com/workingpapers/download. Not\% 20by\% 20the\% 20Book.

Burgoon, J., Adkins, M., Kruse, J., Jensen, M. L., Meservy, T., Twitchell, D. P., ... \& Younger, R. E. (2005, January). An approach for intent identification by building on deception detection. In Proceedings of the 38th Annual Hawaii International Conference on System Sciences (pp. 21a-21a). IEEE.

Chaffey, D. (2016). Global social media research summary 2016. Smart Insights: Social Media Marketing.

Fox, F. E., Morris, M., \& Rumsey, N. (2007). Doing synchronous online focus groups with young people: Methodological reflections. Qualitative health research, 17(4), 539-547.

Galán-García, P., Puerta, J. G. D. L., Gómez, C. L., Santos, I., \& Bringas, P. G. (2016). Supervised machine learning for the detection of troll profiles in twitter social network: Application to a real case of cyberbullying. Logic Journal of the IGPL, 24(1), 42-53.

Grazioli, S., \& Jarvenpaa, S. L. (2000). Perils of Internet fraud: An empirical investigation of deception and trust with experienced Internet consumers. IEEE Transactions on Systems, Man, and Cybernetics-Part A: Systems and Humans, 30(4), 395-410.

Gurajala, S., White, J. S., Hudson, B., \& Matthews, J. N. (2015, July). Fake Twitter accounts: profile characteristics obtained using an activity-based pattern detection approach. In Proceedings of the 2015 International Conference on Social Media \& Society (pp. 1-7).

Haimson, O. L., \& Hoffmann, A. L. (2016). Constructing and enforcing" authentic" identity online: Facebook, real names, and non-normative identities. First Monday.

Hancock, J. T., \& Toma, C. L. (2009). Putting your best face forward: The accuracy of online dating photographs. Journal of Communication, 59(2), 367-386.

Hirschi, T. (1969). Causes of delinquency. Piscataway.

Humpherys, S. L., Moffitt, K. C., Burns, M. B., Burgoon, J. K., \& Felix, W. F. (2011). Identification of fraudulent financial statements using linguistic credibility analysis. Decision Support Systems, 50(3), 585-594.

Jin, L., Wang, L., Zhang, X., Liu, Y., Dai, X., Gao, H., \& Liu, G. (2021). Fully spin-polarized Weyl fermions and in/out-of-plane quantum anomalous Hall effects in a two-dimensional d 0 ferromagnet. Nanoscale, 13(11), 5901-5909.

Kapidzic, S., \& Herring, S. C. (2015). Race, gender, and self-presentation in teen profile photographs. New Media \& Society, 17(6), 958-976.

Kapidzic, S., \& Herring, S. C. (2015). Race, gender, and self-presentation in teen profile photographs. New Media \& Society, 17(6), 958-976.

Kaplan, A. M., \& Haenlein, M. (2010). Users of the world, unite! The challenges and opportunities of Social Media. Business horizons, 53(1), 59-68.

Kaplan, A. M., \& Haenlein, M. (2010). Users of the world, unite! The challenges and opportunities of Social Media. Business horizons, 53(1), 59-68.

Keijsers, L., Branje, S. J., VanderValk, I. E., \& Meeus, W. (2010). Reciprocal effects between parental solicitation, parental control, adolescent disclosure, and adolescent delinquency. Journal of Research on Adolescence, 20(1), 88-113.

Kim, J. L., \& Ward, L. M. (2004). Pleasure reading: Associations between young women's sexual attitudes and their reading of contemporary women's magazines. Psychology of women quarterly, 28(1), 48-58.

Kim, J. L., \& Ward, L. M. (2004). Pleasure reading: Associations between young women's sexual attitudes and their reading of contemporary women's magazines. Psychology of women quarterly, 28(1), 48-58.. 
Lenhart, A., \& Madden, M. (2007). Social networking websites and teens: An overview.

Lu, S., Tsechpenakis, G., Metaxas, D. N., Jensen, M. L., \& Kruse, J. (2005, January). Blob analysis of the head and hands: A method for deception detection. In Proceedings of the 38th Annual Hawaii International Conference on System Sciences (pp. 20c-20c). IEEE.

MA, X. H., \& LEI, L. (2010). Adolescents' internet morality and deviant behavior online. Acta Psychologica Sinica, 42(10), 988.

Meservy, T. O., Jensen, M. L., Kruse, J., Burgoon, J. K., Nunamaker, J. F., Twitchell, D. P., ... \& Metaxas, D. N. (2005). Deception detection through automatic, unobtrusive analysis of nonverbal behavior. IEEE Intelligent Systems, 20(5), 36-43.

Mitchell, K. J., Ybarra, M. L., \& Korchmaros, J. D. (2014). Sexual harassment among adolescents of different sexual orientations and gender identities. Child abuse \& neglect, 38(2), 280-295.

Nahari, G., \& Nisin, Z. (2019). Digging further into the speech of liars: Future research prospects in verbal lie detection. Frontiers in Psychiatry, 10, 56.

Nain, S. 2014. Ten negative effects of internet on students. Retrieved from: http://lists 10.com/1o-negative-effects-internet-students/

Roberts, S. G., \& Dunbar, R. I. (2011). Communication in social networks: Effects of kinship, network size, and emotional closeness. Personal Relationships, 18(3), 439-452.

Smith, P. K., Mahdavi, J., Carvalho, M., Fisher, S., Russell, S., \& Tippett, N. (2008). Cyberbullying: Its nature and impact in secondary school pupils. Journal of child psychology and psychiatry, 49(4), 376-385.

Solorio, T., Hasan, R., \& Mizan, M. (2013). Sockpuppet detection in wikipedia: A corpus of realworld deceptive writing for linking identities. arXiv preprint arXiv:1310.6772.

Solorio, T., Hasan, R., \& Mizan, M. (2013, June). A case study of sockpuppet detection in wikipedia. In Proceedings of the Workshop on Language Analysis in Social Media (pp. 59-68).

Toma, C. L., Hancock, J. T., \& Ellison, N. B. (2008). Separating fact from fiction: An examination of deceptive self-presentation in online dating profiles. Personality and Social Psychology Bulletin, 34(8), 1023-1036.

Tsikerdekis, M., \& Zeadally, S. (2014). Multiple account identity deception detection in social media using nonverbal behavior. IEEE Transactions on Information Forensics and Security, 9(8), 1311-1321.

Tsikerdekis, M., \& Zeadally, S. (2014). Online deception in social media. Communications of the ACM, 57(9), 72-80. .

van der Walt, E., \& Eloff, J. (2017). Creating an environment for detecting Identity Deception. Technische Berichte des Hasso-Plattner-Instituts für Digital Engineering an der Universität Potsdam, 3.

Wang, G. A., Chen, H., Xu, J. J., \& Atabakhsh, H. (2006). Automatically detecting criminal identity deception: an adaptive detection algorithm. IEEE Transactions on Systems, Man, and Cybernetics-Part A: Systems and Humans, 36(5), 988-999.

Ybarra, M. L., Diener-West, M., and Leaf, P. J. (2007). Examining the overlap in internet harassment and school bullying: Implications for school intervention. Journal of Adolescent Health, 41(6), S42-S50. doi:10.1016/j.jadohealth.2007.09.004. 